\title{
STUDI TENTANG STANDAR SEPATU KANVAS UNTUK EKSPOR
}

\author{
Oleh : Sri Bandi, Adi Slamet Supriyadi, Hastungkoro Wijaya Wardani
}

\begin{abstract}
In this study, 10 pairs of canvas shoes with rubber soles of various trade marks were tested. The samples were taken either from manufacturers or markets in DKI Jakarta or DIY, the test method used was as stated in SII 1406-85. The objective of this study is to compile a concept of standard for export quality canvas shoes. The test results of canvas with rubber soles can be provided as follows the portion bursting strength $(15,839-22,4737) \mathrm{kg} / \mathrm{cm}^{3}$; breaking load of shoe laces 463,31 $643,846 \mathrm{~N}$; the bottom portion - the thickness of soles without treat $(1,31-2,79)$ $\mathrm{mm}$; tensile strength $(6,25-11,94) \mathrm{N} / \mathrm{mm}^{2}$; elongation at break $(202,45$ $522,93) \%$; permanent set $50 \%(1,46-5,22)$; specific gravity $(1,15-1,29)$; Grasselli abrasion resistance $(0,49-3,25) \mathrm{mm} / \mathrm{kgm}$; tear strength $(2,48-6,46) \mathrm{N} /$ $\mathrm{mm}^{2}$; flexing resistance no cracks permitted; hardness $(54,17-72,86)$ shore A. The 10 pairs of canvas shoes were also visually inspected according to SII 1406 85 and they fulfilled the requirements. Besides testing some standards concepts from other countries such as JIS (Japanese Industrial Standard), IS (Indian Standard), CNS (China National Standard), KS (Korean Standard) were also studied and based on them, a conclusion can be drawn as follows according to JIS. S $5002-86$, it was necessary to inspect them visually, to test their bursting strength, tensile strength and hardness; according to IS 375 - 1966 it was necessary to inspect them visually to test their thickness, specific gravity, hardness, abrasion resistance and flexing resistance according to CNS UDC 685 - 31 it was necessary to inspect them visually, to test their thickness, tensile strength, and elongation at break, according to KS M 6522 - 74 it was necessary to inspect them visually, to test their bursting strength, elongation at break and tensile strength.
\end{abstract}




\section{PENDAHULUAN}

Sepatu kanvas dengan sol karet dewasa ini tumbuh dan berkembang dengan pesatnya, maka memberikan harapan yang cerah dan menggembirakan bagi para produsen sepatu tersebut.

Pertumbuhan dan perkembangannya yang menggembirakan ini perlu diimbangi dengan pengawasan mutunya. Hal ini sangat penting untuk menjaga kontinuitas mutu serta kelangsungan hidup dari perusahaan tersebut, karena setiap usaha pasti ada persaingannya, apalagi komoditi tersebut merupakan mata dagangan yang diekspor.

Untuk mendapatkan peluang ekspor di pasaran luar negeri bukanlah suatu hal yang mudah, peluang tersebut akan dapat tercapai apabila dapat memenuhi persyaratan-persyaratan yang telah ditentukan yaitu disamping dari segi harga juga dari segi mutunya.

Agar sepatu kanvas dengan sol karet yang diekspor tersebut dapat diterima di pasaran luar negeri, maka perlu diketahui persyaratan-persyaratan atau standar mutu yang harus dipenuhi oleh sepatu kanvas untuk diekspor. Disamping itu juga perlu diperhatikan kontinuitas mutunya untuk menjaga kelangsungan ekspor tersebut.

\section{TINJAUAN PUSTAKA}

Mutu sepatu kanvas ditentukan oleh beberapa faktor antara lain mutu bahan, mutu pengerjaan, kenampakan serta keenakan pakai dari sepatu tersebut. Faktor penentu mutu tersebut yang penting meliputi bursting strength, separating test, tensile strength, elongation at break colour fastness, breaking strength, tear strength untuk bagian atas dan thickness, tensile strengt, elongation, hardness, abrassion, flexing resistance, specific gravity untuk bagian bawah.

Dalam JIS S 5002 - 1986 : Canvas boots and shoes guna menjamin mutu penggunaan sepatu, maka retak lentur ditetapkan tidak boleh retak, bila dilakukan uji retak lentur $150 \mathrm{kcs}$, mengingat hal itu merupakan bagian yang sering mengalami stress pada pema-kaian. Kenampakan sepatu harus baik, tidak cacat sehingga keenakan pakai pada sepatu selalu terjamin.

CNS UDC 685.31 sepatu olah raga dengan bagian atas dari kanvas dipersyaratkan bahwa kenampakan sepatu harus baik tidak boleh ada lapisan atau hiasan yang mudah mengelupas, tidak boleh ada kerutan atau keretakan.

Retak lentur merupakan faktor utama mutu sepatu. Sol diambil langsung dari sepatu, kemudian dibengkuk sebesar $60^{\circ}-90^{\circ}$ tanpa tekanan yang dipaksakan akan mampu mengecek pengaruh desain, seperti yang dipersyaratkan pada India Standard 3735-1966. Korean Standard M. 6522-74, Canvas Shoes with rubber soles mensyaratkan kenampakan sepatu harus baik, tidak boleh cacat, retak, serasi antara kiri dan kanan. Sepatu harus tahan terhadap perubahan cuaca dan minyak pelumas.

\section{METODE PENELITIAN}

A. Bahan dan Peralatan

1. Bahan :

10 pasang sepatu kanvas kualitas ekspor dari berbagai merk diambil dari pasaran yang ada di daerah DKI Jakarta dan Daerah Istimewa Yogyakarta.

2. Peralatan :

Alat uji ketahanan letup (Bursting tester)

Alat ukur tebal (jangka sorong) dengan ketelitian $0,01 \mathrm{~mm}$

Alat uji perpanjangan putus, tegangan putus, ketahanan sobek (Tensile strength tester).

Alat uji kekerasan sol (Hardness tester Shore A)

Alat uji ketahanan kikis (Abrassion tester) cara Grasselli

Alat uji ketahanan retak lentur ( Ross flexing)

Alat uji perpanjangan tetap ( permanent set)

Dumbell

Penggaris

Cutter

Gunting

\section{B. Pelaksanaan Pengujian}

Pengujian yang dilakukan untuk sepatu kanvas untuk ekspor meliputi pengujian fisika antara lain

a. Bagian atas

1. Ketahanan letup (kain bagian atas)

2. Tali sepatu

2.1. Bahan

2.2. Beban tarik

b. Bagian bawah

1. Sol luar

1.1. Tebal

1.2. Tegangan putus

1.3. Perpanjangan putus

1.4. Perpanjangan tetap $50 \%$

1.5. Berat jenis

2. Foksing

2.1. Tebal

2.2. Ketahanan rekat
1.6. Kekerasan

1.7. Ketahanan kikis

1.8. Ketahanan sobek

1.9. Ketahanan retak lentur 


\section{Cara Pengujian}

Sebelum dilakukan pengujian, contoh sepatu diamati lebih dahulu terhadap ada tidaknya kerusakan yang berupa lubang, sobek dan adanya benda asing maupun cacat lainnya. Contoh uji harus bebas dari kerusakan.

Siapkan contoh uji tersebut dengan bentuk dan ukuran sesuai ketentuan, selanjutnya kondisikan cuplikan tersebut pada suhu $27 \pm 2{ }^{\circ} \mathrm{C}$ dengan kelembaban relatif $60 \pm 5 \%$ selama minimal 24 jam.

1. Tali sepatu

Bahan : Bakar tali sepatu, amati abu yang diperoleh, apabila serat terbakar dengan cepat, meninggalkan abu berbentuk serat dan berbau seperti kertas terbakar, maka keadaan ini menunjukkan serat cellulose.

Beban tarik sampai putus

Pengujian dilakukan dengan pesawat uji kuat tarik. Pasang tali sepatu hingga jarak pada penjepit $20 \mathrm{~cm}$. Penarikan dikerjakan dengan kecepatan $25 \mathrm{~cm} /$ menit sampai cuplikan putus. Amati beban yang diperlukan, lakukan 3 kali pengujian.

\section{Tebal sol luar}

Ukur mempergunakan micrometer dengan ketelitian $0,01 \mathrm{~mm}$. Tebal contoh uji dapat dibaca pada skala. Lakukan 3 kali pengukuran dan hasilnya diratarata.

3. Tegangan putus dan perpanjangan putus

Pengujian dilakukan dengan alat uji ketahanan tarik. Potong contoh dalam bentuk dayung (dumbell) memakai pisau pons dengan bentuk dan ukuran sebagai berikut :

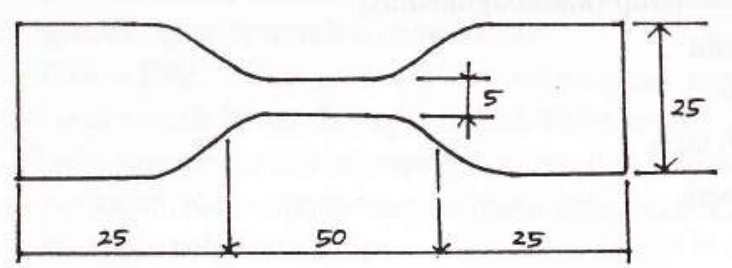

\section{Gambar 1. Bentuk Contoh Uji}

Beri tanda dua garis sejajar pada cuplikan berjarak $25,4 \mathrm{~mm}$, simetris di tengah-tengah dayung. Ukur lebar dan tebal cuplikan di tempat a, b, c, kemudian pasang pada alat sehingga jarak antara kedua jepitan $50 \mathrm{~mm}$. Penarikan dikerjakan dengan kecepatan $25 \pm 1 \mathrm{~cm} / \mathrm{menit}$ sampai cuplikan putus. Perhitungan (yang dicapai dan beban yang diperlukan)
Tegangan putus $=\frac{\mathrm{F}}{\mathrm{t} \times \mathrm{w}} \mathrm{kg} / \mathrm{cm}^{2}$

$$
\text { L1 - Lo }
$$

Perpanjangan putus $=$

dimana,

F : beban yang diperlukan untuk menarik cuplikan sampai putus, $\mathrm{kg}$.

t : tebal cuplikan, $\mathrm{cm}$.

w : lebar cuplikan, $\mathrm{cm}$.

Lo : panjang mula-mula antara dua tanda garis

L1 : panjang cuplikan antara dua garis, pada waktu putus

4. Perpanjangan tetap, $50 \%$

Alatnya suatu plat logam berbentuk persegi panjang beru-kuran panjang 45 $50 \mathrm{~cm}$, lebar $30-35 \mathrm{~cm}$, dengan memanjang kiri dan kanan, tinggi $2 \mathrm{~cm}$ dan lebar $2 \mathrm{~cm}$.

Ukuran cuplikan panjang $10 \mathrm{~cm}$

$\begin{array}{lll}\text { Lebar } & 4 & \mathrm{~cm} \\ \text { Tebal } & 3 & \mathrm{~cm}\end{array}$

Buat garis sejajar pada cuplikan dengan jarak $5 \mathrm{~cm}$. Pasang cuplikan pada alat dengan menggunakan klem yang satu dipindahkan, sehingga cuplikan ditarik sampai perpanjangan $50 \%$. Dalam keadaan tertarik biarkan selama 1 jam. Ukur jarak antara dua garis sejajar.

$$
\text { Perpanjangan tetap }=\frac{\text { t1 }- \text { to }}{\text { to }} \times 100 \%
$$

dimana,

t1 : panjang antara dua garis sejajar setelah pengujian

to : panjang antara dua garis sejajar sebelum pengujian

5. Bobot jenis

Timbang cuplikan dengan berat \pm 2 gr. Gantungkan cuplikan, masukkan dalam air yang berada dalam gelas piala, tentukan beratnya.

$$
\text { Bobot Jenis }=\frac{w 1}{(w 1 \times w 2)} \times \text { bobot jenis air }
$$




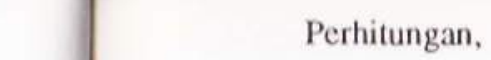

Bobot Jenis $=\frac{}{(w 1 \times w 2)} \times \mathrm{g} / \mathrm{cm}^{3}$

dimana

w1 $=$ berat cuplikan di udara

w2 $=$ berat cuplikan di dalam air.

Hasil uji cuplikan adalah rata-rata dari 3 kali pengujian.

\section{Kekerasan}

Pengujian dilakukan dengan alat uji Hardness tester shore A Durometer.

Cuplikan harus memenuhi persyaratan sebagai berikut :

- ketebalan contoh sekurang-kurangnya $6,3 \mathrm{~mm}$ contoh yang tipis boleh disusun/ ditumpuk untuk mencapai ketebalan tersebut.

- lebar contoh sekurang-kurangnya $2,54 \mathrm{~cm}$.

- Pengujian tidak boleh dilakukan pada tempat yang kurang dari $12,7 \mathrm{~mm}$ dari tepi permukaan contoh dan luas permukaan uji tidak boleh kurang dari tepi permukaan contoh dan luas permukaan kaki penekan.

- Permukaan contoh harus rata, karena kaki penekan alat harus sejajar benar dengan permukaan contoh.

Pengujian dilakukan sebagai berikut:

Letakkan contoh uji diatas dasar yang keras dan datar. Pegang alat tegak lurus dengan erat oleh ibu jari tengah serta jari manis. Letakkan telunjuk pada bagian alas alat. Tekan alat pada permukaan contoh sampai kaki penekan alat menyentuh dan sejajar benar dengan permukaan contoh. Besamya tekanan yang diberikan kaki penekan pada permukaan contoh harus menurut standar kekuatan penekan tertentu (60 shore). Pembacaan skala dilakukan segera setelah diperoleh kontak yang erat dan sejajar tadi. Lakukan 3 kali pengujian dan diambil rata-ratanya.

7. Ketahanan kikis Grasselli

Pengujian ketahanan kikis dengan cara Grasselli

Sebelum pengujian dimulai, tentukan dulu bobot jenis contoh. Kemudian buat cuplikan dengan ukuran : panjang dan lebar masing-masing $2 \mathrm{~cm}$, tebal $1 \mathrm{~cm}$. Pasang cuplikan pada tempatnya, satu kali pengujian dapat dipasang dua buah cuplikan. Jalankan mesin selama 2 menit untuk meratakan cuplikan. Keluarkan cuplikan, kemudian timbang dengan teliti, lalu pasang lagi pada tempatnya semula. Jalankan mesin selama 6 menit untuk mengikis cuplikan. Waktu mesin berjalan, atur neraca pegas sehingga lengan neraca letaknya tetap seimbang benar-benar, yaitu terletak diantara dua pena. Pasang pompa angin untk membersihkan kotoran atau debu yang menempel akibat terjadinya penggosokan tersebut. Pembacaan timbangan neraca pegas dilakukan tiap-tiap menit dan dicatat. Setelah 6 menit keluarkan kedua cuplikan dan timbang kembali dengan teliti.

$$
\text { Ketahanan kikis }=\frac{\text { Wo }-\mathrm{Wl}}{\mathrm{t} \times \mathrm{Bj} \times \mathrm{E}} \times \mathrm{mm}^{3} / \mathrm{kgm}
$$

dimana,

E : $\quad 37 \times 2 \times(a P+b Q+M) \mathrm{kg} /$ menit

Wo : berat mula-mula setelah diratakan selama 2 menit, gram

W1 : berat setelah pengikisan, gram

t : waktu pengikisan, 6 menit

$\mathrm{Bj}$ : bobot jenis, $\mathrm{gr} / \mathrm{cm}^{3}$

a : jarak dari neraca pegas sampai titik pusat lingkaran $=0,255 \mathrm{~m}$

b : jarak dari beban sampai titik pusat lingkaran $=0,381 \mathrm{~m}$

$P$ : pembacaan rata-rata dari neraca pegas, Kcs

Q : berat beban rata-rata, $\mathrm{kg}$

$\mathrm{M}$ : momen mesin, nol

8. K̈etahanan sobek

Ketahanan sobek adalah beban yang diperlukan untuk menarik sampai putus suatu cuplikan yang telah dilubangi memakai pons ditengah-tengah cuplikan sepanjang $5 \mathrm{~mm}$ tegak lurus pada arah tarik. Alat yang digunakan Tensiometer Zwik atau Shopper kecil, pisau pons untuk membuat cuplikan, pengukur tebal, Mikroskop dengan perlengkapan mikrometer untuk mengukur lebar cuplikan yang tersobekkan. Buat cuplikan berbentuk empat persegi panjang dengan ukuran panjang $6 \mathrm{~cm}$, lebar $1 \mathrm{~cm}$ dan tebal $\pm 2 \mathrm{~mm}$. Buat tanda arah sejajar dengan panjang cuplikan. Buat keratan ditengah-tengah cuplikan tegak lurus pad sumbu panjang selebar $5 \mathrm{~mm}$. Ukur tebal cuplikan pada bagian yang terdapat keratan. Pasang kedua ujung cuplikan pada penjepit-penjepit mesin Zwik atau shopper kecil dan selanjutnya sama seperti pada pengujian tegangan putus. Tarik cuplikan sampai putus dan catat beban yang diperlukan. Ukur lebar cuplikan yang tersobekkan memakai mikrometer mikroskup.

Hasil pengujian,

Ketahanan sobek $=\frac{\mathrm{F}}{\mathrm{t} \mathrm{xw}} \quad \mathrm{kg} / \mathrm{cm}$

dimana,

F : beban untuk menarik sampai putus, $\mathrm{kg}$

t : tebal cuplikan, $\mathrm{cm}$

w : lebar yang tersobekkan, $\mathrm{cm}$

Hasil uji adalah rata-rata dari ketiga kali pengukuran. 
9. Ketahanan retak lentur, $150 \mathrm{kcs}$

Alat yang digunakan Flexometer

Ukuran cuplikan

Panjang $150 \mathrm{~mm}$; Lebar $20 \mathrm{~mm}$; Tebal $6 \mathrm{~mm}$

Buat suatu bulatan (lingkaran) dari kertas karton yang berukuran $7 \mathrm{x}$ tebal cuplikan. Pasang pada Flexometer, cuplikan melingkari setengah lingkaran dari karton. Keluarkan karton tersebut lenturkan sampai 150.000 pelenturan, amati ada tidaknya keretakan.

\section{Tebal Foksing}

Untuk mengukur tebal digunakan alat Mikrometer dengan ketelitian sampai $0,1 \mathrm{~mm}$. Lepaskan foksing dari sepatunya ukur ketebalannya letakkan alat ukur mikrometer pada posisi mendatar. Alat penekan dikontakkan kemudian foksing diletakkan dibawahnya dan alat penekan dibiarkan menekan pada alat foksing. Baca tebal foksing pada skala, lakukan tiga kali pengukuran pada tempat yang berbeda dan hasil pengujian merupakan hasil dari nilai rata-rata.

\section{Ketahanan rekat foksing}

Pengujian dilakukan dengan pesawat uji kuat tarik. Buat 3 cuplikan panjang 50 $\mathrm{mm}$ dan lebar $6 \mathrm{~mm}$, buka lapisan cuplikan sepanjang $10 \mathrm{~mm}$, pasang cuplikan pada penjepit yang ada pada alat, lapisan yang satu tetap yang lain ditarik kebawah. Jalankan alat penarik dengan kecepatan $150 \mathrm{~mm} / \mathrm{menit}$ sampai lapisan terbuka solnya, catat beban yang digunakan. Hasil pengujian adalah rata-rata dari tiga kali pengujian yang telah dicatat.

\section{Ketahanan letup}

Pengujian ini dilakukan dengan pesawat letup (bursting strength tester $x a u$ Mullen tester), Contoh dipotong bentuk persegi empat dengan ukuran (10 $\mathrm{x}$ $10) \mathrm{cm}^{2}$. Diukur tebalnya pada bagian tengah. Selanjutnya contoh dipasang pada pesawat, jalankan dan contoh menerima tekanan sampai contoh meletup atau pecah. Hasil tekanan (P) dibaca sebagai PSI atau dapat diubah menjadi kg/ $\mathrm{cm}^{2}\left(1 \mathrm{PSI}=0,0703 \mathrm{~kg} / \mathrm{cm}^{2}\right)$. Hasil uji dinyatakan dengan PSI atau kg/cm ${ }^{2}(\mathrm{MP}$ $=\mathrm{P} / \mathrm{T})$

$\mathrm{P}=$ tekanan sampai contoh meletup

$\mathrm{T}=$ tebal contoh 


\section{PEMBAHASAN}

Dari pengujian 10 pasang sepatu kanvas dengan sol karet untuk ekspor didapat hasil sebagai berikut:

1. Ketahanan letup untuk bagian atas diperoleh hasil : $15,83-22,47 \mathrm{~kg} / \mathrm{cm}^{2}$ dan persyaratan dari JIS.S. $5002-86 \mathrm{~min} .10 \mathrm{~kg} / \mathrm{cm}^{2}$ dan menurut KS.M.6522-74 $\min .17 \mathrm{~kg} / \mathrm{cm}^{2}$.

2. Sedangkan untuk sol luar hasilnya bervariasi:

tebal sol tanpa kembangan 1,31 - 2,79 mm, persyaratan SII.1406-1985 min. 2,0 $\mathrm{mm}$, dari CNS.UDC.685.31 adalah 2,0 mm.

tegangan putus $6,25-11,94 \mathrm{~N} / \mathrm{mm}^{2}$, persyaratan SII.1406-1985 min. $10 \mathrm{~N} /$ $\mathrm{mm}^{2}$, JIS.S.5002-1986 min. $8 \mathrm{~N} / \mathrm{mm}^{2}$, CNS. EDC.685.31 adalah $9 \mathrm{~N} / \mathrm{mm}^{2}$ sedang dari KS.M 6522-74 $\mathrm{min} .6 \mathrm{~N} / \mathrm{mm}^{2}$.

ketahanan sobek $(2,48-6,45) \mathrm{N} / \mathrm{mm}^{2}$ persyaratan SII.1406-1985 min. 5,8 N/ $\mathrm{mm}^{2}$.

3. Sedang untuk uji yang lain seperti : perpanjangan putus, perpanjangan tetap $50 \%$, berat jenis, kekerasan dan ketahanan retak lentur, semua memenuhi persyaratan SII.1406-1985 Sepatu kanvas untuk Olah Raga.

\section{KESIMPULAN}

1. Dari 10 pasang sepatu kanvas untuk ekspor yang diuji sebagian besar telah memenuhi persyaratan SII.1406-1985, JIS.S.5002-1986, IS.3735-1966, CNS.UDC.685.31 dan KS.M.6522-74, kecuali untuk uji ketahanan kikis Grasselli dan ketahanan sobek.

2. Ketahanan letup untuk bagian atas sepatu $(15,83-22,47) \mathrm{kg} / \mathrm{cm}$ _ dapat memenuhi persyaratan pada JIS.S.5002-1986 dan KS.M. 6522-1974.

3. Pada umumnya sepatu kanvas untuk ekspor tidak memakai foksing hal ini terbukti dari 10 pasang sepatu yang diuji hanya $40 \%$ saja yang memakai foksing.

4. Hasil studi tentang standar Sepatu Kanvas Untuk Ekspor ini telah dipakai untuk menyusun rancangan Standar Industri Indonesia tentang Sepatu Kanvas Untuk Ekspor.

\section{DAFTAR PUSTAKA}

1. CNS.S.2010, Testing Standard for Sport Shoes (Canvas High Tops).

2. IS.3735-1966, Specification for Canvas Shoes, Rubber Sole.

3. JIS.S. 5002-1986, Canvas Boots and Shoes.

4. KS.M.6522-74, Canvas Shoes With Rubber Soles.

5. SII.1406-1985, Sepatu Olah Raga dari Kanvas dengan Sol Karet Sistem Cetak Vulkanisasi. 